\title{
Main Health Disorders and the Socioeconomic Costs for Drugs Used and Reimbursed for the Patients during the Period 2008-2012
}

\author{
Dr. Elidiana Bashi ${ }^{1}$
}

\author{
Dr. Zamira Shabani²
}

PHD student Alida Sina ${ }^{3}$

\section{Student Arlinda Ramaj ${ }^{4}$}

\begin{abstract}
${ }^{1}$ Finance lecturer - University "Luigj Gurakuqi”, Sheshi "2 Prilli”, Shkoder, elidianapema@yahoo.com. 2University “Luigj Gurakuqi”, Sheshi "2 Prilli”, Shkodër, shabanizamira@yahoo.com .

3Health insurance institute, alidasina@yahoo.com

4Medicine student, arlindaramaj@yahoo.com
\end{abstract}

Doi:10.5901/ mjss.2014.v5n13p0526

\begin{abstract}
The mental health disorders affect people of all ages in all countries and causing pain to families and society, as well as to individuals. The mental, physical and social aspects of people are deeply related to many socio - economic factors of country's development. The society has become more conscious that the health insurance scheme is crucial for welfare of all people, society and countries. The number of patients that suffer different diseases is increasing with population aging and deterioration of social and economic problems. Different health disorders cause disabilities in work performance. The aim of this study is to describe the socioeconomic effects of reimbursement scheme of drugs in Shkodra city. This paper is a depiction of economic costs for drugs used and reimbursed for the patients during the period 2008- 2012. In this study we have described all hospitalized cases at the Regional Hospital of Shkodra and all cases treated by the family doctors in Shkodra city.
\end{abstract}

Keywords: mental disorders, drugs, reimbursement scheme, health care, PHI - Public health institution, etc .

\section{Methodology}

The elaboration of data was made by Microsoft excel 2007. During this paper we have used primary and secondary data. Secondary data were collected from different bulletins, and magazines in Albania. The primary data were collected from the main database of drug reimbursement scheme in Shkodra office directory. The collection of primary data was made through direct interviews - and personal meeting with employees of the reimbursement of drug directory - Shkodra branch.

\section{Research question}

Did the improvement of the drugs list reimbursement from year to year improved the health of inhabitants in Shkodra?

\section{Organization of Health Care System in Albania}

Health care system in Albania is mainly public. The state insures the main part of the services that is offered to the population, for the promotion, prevention, diagnostic and salvation of different illnesses. Private sector is still at his first steps, and it covers mainly the pharmacy sector. In public sector the leader role is played mainly from the health ministry of Albania, that is the main institution that creates the politics and strategies for health system, for its regulation and coordination of the role of all actors, within and outside this system.

Diagnostic and curative health service is organized on three levels: primary service, secondary hospital service, and tertiary hospital service.

Public health services and promotion offered under the primary health care and supervised and supported by public health institution $(\mathrm{PHI})$. 
Excluding the capital city - Tirana, in other cities in Albania the Public Health Instituon is organized in Public Health care directories - that has the main duty to reconcile all the health services of the city.

\section{The Public Health Care Institution}

Health care insurance in Albanian republic, is obliged by the law of social insurance care in the Albanian republic No. 7870, date 13.10.1994. Its Bismarkian type system. Its was first implementd on 1 March 1995 as the main mechanism in health insurance system reforming. The reforms to this system include the way this system is financed by increasing the main sources to this system, and towards improvement of the service qualities. Institucione nacionale

The public health institution - is under tuition of the health ministry. Its duties include studing and controlling the risk factors, surveying the contagious diseases, laboratory references and managing vaccination of population programs.

\section{National Center of Drug Control}

This center is the responsible institute for controlling of each operation in pharmaceutical field. It makes control to:

a. fabrication activities, to its facilities and equipment

b. wholesale and retail trading and storage conditions of medicines,

c. Drug raw materials and auxiliary materials packer

d. imports of drugs from all licensed entities.

\section{The Reimbursement Health Care Scheme in Albania}

Law no 10383 date February 24, 2011 "For obligative health insurance in Albanian Republic", that was implemented in March 2013, prescribes the health insurance scheme as below:

This law tries to have a wide population range that has a universal coverage scheme. This law divides the insurers into two parts: persons economically active and persons not economically active, where we can find sub divisions of these to big groups according to their special economic and social characteristics. Both categories mentioned, are included to this insurance scheme, with the unique difference that for the first group of people they pay for themselves, and on the other hand for the second group pays the second category pays the state.

Non active economically population are handled with care from this scheme - to assure that this can be more inclusive for this category in need, such as:

1. Persons that profit from the social insurance institute

2. Persons that profit economic support or payment for limited physic capabilities in accordance with the appropriate legislation

3. Persons registered as unemployed - job searchers in the national service of employment

4. Foreign citizens in Albanian Republic - emigrants from foreign countries

5. Kids under the age 18 years old

6. Pupils and students under 25 years old, with the condition that they profit from this scheme if they do not have income from economic ectivities

7. Special categories of people such as: blinds, orphans etc.

The government pays about $76 \%$ of total funds by covering the need categories and only $24 \%$ are covered from the contributions.

The persons that are not included at the first and second category above mentioned, for different cases, have the right to join voluntary in the obligative health insurance scheme. In this category are included people that live from immigration, or householders that have chosen not to work, Albanian students from abroad for the time they spend in Albania, etc. Persons self insured - have the same rights and conditions to profit from the law as the same other people that paw their contribution in an obligative manner.

For the first time at this law is foreseen realization of the register of insured persons, their identification, and giving them a special identifying number. At this law was foreseen the register of health insurance givers. The rate of obligative health insurance is $3.4 \%$ of the basis for insurance calculations for all the categories covered from the health insurance scheme. For the employers, the contributions are paid at $50 \%$ from the employee and $50 \%$ from the employer. The improved law did not bring any contribution rate change and asks for a unification of the basis of health insurance employers and self voluntaries. The collection of this insurance rate is foreseen to be done from the tax directorates in different cities in whole republic. 
Table: Total income reported from General Tax directorate and social insurance office - both with health insurance office, during $2007-2012$.

In $000 \mathrm{ALL}$

\begin{tabular}{|c|l|c|c|c|c|c|c|}
\hline No & Subjects & $\mathbf{2 0 0 7}$ & $\mathbf{2 0 0 8}$ & $\mathbf{2 0 0 9}$ & $\mathbf{2 0 1 0}$ & $\mathbf{2 0 1 1}$ & $\mathbf{2 0 1 2}$ \\
\hline 1 & Budgeting & $1,765,936$ & $1,954,231$ & $2,337,487$ & $2,500,809$ & $2,640,527$ & $2,703,576$ \\
\hline 2 & Not budgeting & 386,438 & 749,071 & 267,800 & 246,062 & 325,075 & 282,554 \\
\hline 3 & Private firms & $1,039,172$ & $1,389,253$ & $2,323,339$ & $2,376,710$ & $2,508,861$ & $2,734,887$ \\
\hline 4 & Individuals From cities & 663,670 & 557,295 & 7,483 & $1,184,288$ & 883,062 & 972,943 \\
\hline 5 & Individuals from countries & 197,217 & 182,618 & 192,241 & 192,054 & 129,026 & 80,045 \\
\hline 6 & Voluntaries & 4,256 & 4,126 & 6,940 & 13,411 & 12,578 & 11,453 \\
\hline & Total & $\mathbf{4 , 0 5 6 , 6 8 8}$ & $\mathbf{4 , 8 3 6 , 5 9 3}$ & $\mathbf{6 , 1 3 5 , 2 8 9}$ & $\mathbf{6 , 5 1 3 , 3 3 5}$ & $\mathbf{6 , 4 9 9 , 1 2 9}$ & $\mathbf{6 , 7 8 5 , 4 5 8}$ \\
\hline
\end{tabular}

\section{Source: www. Isksh.com.al}

The table shows that the most significant payments comes from the budgeting institutions an from the private firms. A we can see the voluntary payments are the least figure income. This means that the state should invent a mechanism to make people have more voluntary payments

Table: The number of contributors referring to general tax directory and social insurance institute during $2007-2012$

\begin{tabular}{|c|l|c|c|c|c|c|c|}
\hline No & No on contributers & $\mathbf{2 0 0 7}$ & $\mathbf{2 0 0 8}$ & $\mathbf{2 0 0 9}$ & $\mathbf{2 0 1 0}$ & $\mathbf{2 0 1 1}$ & $\mathbf{2 0 1 2}$ \\
\hline 1 & Budgeting subjects & 140,994 & 127,783 & 125,856 & 133,211 & 138,645 & 138,572 \\
\hline 2 & Not budgeting subjcets & 47,101 & 29,611 & 25,612 & 21,546 & 21,677 & 20,558 \\
\hline 3 & Subject with value added tax & 152,580 & 146,139 & 156,743 & 166,612 & 182,057 & 188,233 \\
\hline 4 & Small businesses & 61,495 & 58,101 & 61,690 & 63,082 & 78,839 & 78,701 \\
\hline 5 & farmers & 61,495 & 55,000 & 60,000 & 49,664 & 56,453 & 48,581 \\
\hline 6 & Voluntaries & 263 & 300 & 500 & 650 & 610 & 1,526 \\
\hline & Total & $\mathbf{4 6 5 , 9 3 5}$ & $\mathbf{4 1 8 , 9 4 2}$ & $\mathbf{4 3 2 , 4 1 0}$ & $\mathbf{4 3 6 , 7 7 5}$ & $\mathbf{4 8 0 , 2 9 2}$ & $\mathbf{4 7 8 , 1 8 3}$ \\
\hline
\end{tabular}

The number of contributers as per the amount paid is the most from budgeting institution and from businesses included at the value added tax system (that means big businesses - referring to the Albanian law on classification of the firms)

\section{Which are the Diseases mostly Reimbursed}

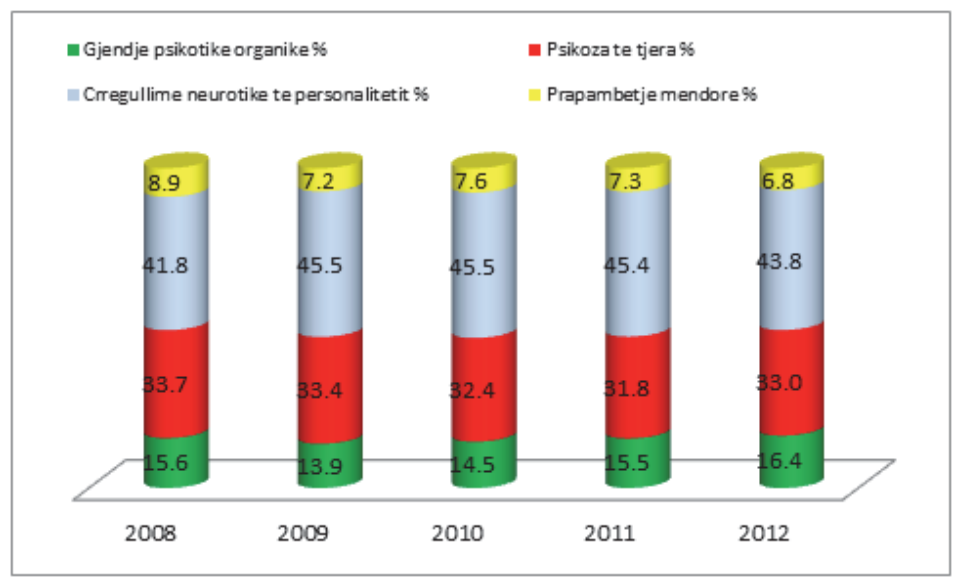

Referring to mental health disorders, you can judge from the chart the most reimbursed illness is other psychosis marked with red, the green one shows organic psychotic state that is increasing from year to year, and in blue there are neurotic disorders on personality, and with yellow mental delay. 
During this paper we emphasized the mental health problems because the cases of these diseases in Shkodra have increased from year $2008-2012$, that is shown as below

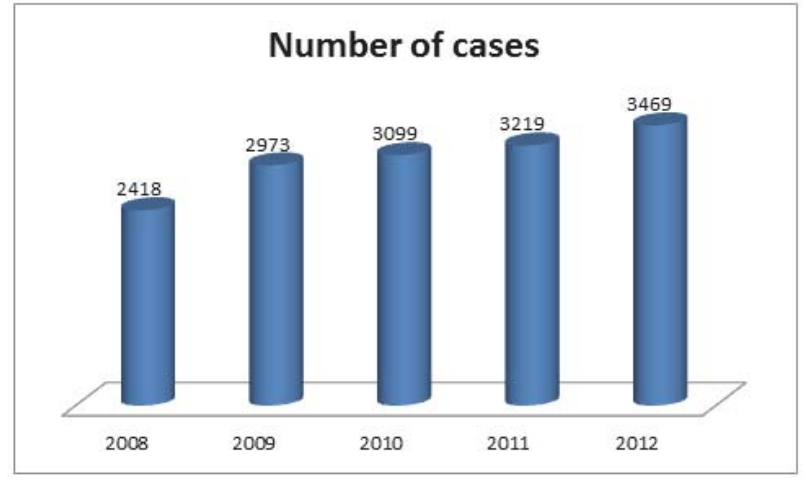

by increasing from year to year the number of these cases, the total bills on reimbursements have increased rapidly by showing that the social health insurance from year to year has increased its gap, because of the number of increased cases of these deseases.

During 2008 about 19,811,731 Albanian leke in reimbursement was spent for the diseases of people that suffer from mental problems and disorders. During 2009, from the budget of PHI was spent about 23,877,431 Albanian leke. During 2010 was spent about 24,789,678 Albanian leke. During 2011 was spent about 27,356,890 Albanian leke and during 2012 was spent about 25, 789,456 Albanian leke.

According to this figures this means that in average PHI has spent on mental health about 8,193 Albanian leke - in 2008, 8,031 - 2009, 7,999 All - 2010, 8,498 All - 2011 and about 7,434 All in 2012.

This means that from 2008 - 2012 the Albanian government has not improved the budget reimbursement for mental health disorders.

\section{Conclusions}

1. Mental health disorders include diseases that are related to the behavior of people. It includes categories that are specially related psychosis, such as: insomnia, depression, different other psychosis etc.

2. It includes mainly young people that remains the best part and the potential parts of generation investments, because they are the new and future employers.

3. Judging from the figures and the chart above, you can see that from the contribution of social health institution in Albanian, the budget of bill reimbursement for such diseases does not surpass the limit of about $5 \%$ reimbursement.

4. No improvement in increasing the figure of bill reimbursement was done from year $2008-2012$.

\section{Recommendations}

1. Mental health is very important to the new generation. More health care has to be directed to this mass from the people. According to the reimbursed bills, it is necessary:

a) To increase the categories of drugs reimbursed related to this diseases

b) More free visits - according to social health, should be offered to people that suffer such diseases. (the payment of this controls should be covered from $\mathrm{PHI}$ )

c) The social health care institute should increase the financial income from voluntaries, because they make about $46 \%$ of people that are included in the health insurance scheme. The ways to increase voluntary to this matter are related to government politics. For example one can be, if you let someone choose from the categories of reimbursement than he will pay the voluntary part very often.

d) More information and publicity from the health insurance institute is needed, because people very often do not even know that they can reimburse drugs. 


\section{Bibliography}

Bundo, Sherif -2012, Fiskaliteti

Hoti llir, -2008, Menaxhimi I sigurimeve

www.isksh.org

Law on Health insurance - republic of Albania 